\title{
INFLUÊNCIA DO CLORETO DE CÁLCIO NO CRESCIMENTO DE EXPLANTES DE Gypsophila paniculata L. (CARYOPHYLLACEAE), CULTIVADOS in vitro.
}

\author{
R. JUN TAKANE \\ Faculdade de Agronomia "Dr. Francisco Maeda", Rua Cel. Flauziano B. Sandoval, 1259 - CEP: 14520-000 - Ituverava \\ K. MINAMI \\ Departamento de Horticultura-ESALO/USP - C.P. 9, CEP: 13418-900 - Piracicaba,SP. \\ A.A.LUCCHESI; M. DE ALMEIDA \\ Departamento de Botanica- ESALQ/USP - C.P. 9, CEP: 13418-900 - Piracicaba,SP
}

RESUMO: Este trabalho teve por finalidade verificar a influência do Cloreto de $\mathrm{Cálcio}\left(\mathrm{CaCl}_{2}\right)$ no crescimento de explantes de Gypsophila paniculata L., cultivados em meio de cultura a fim de fornecer subsídios para a micropropagação desta cultura. Foram utilizados como explantes somente as gemas apicais das plantas em fase de crescimento vegetativo. Os explantes foram inoculados em meio de cultura MS (Murashigue \& Skoog) modificado com diferentes concentraçōes de $\mathrm{CaCl}_{2}:$ a) 440 ; b) 880 ; c) 1.760 ; d) 2.640 e e) $3.520 \mathrm{mg} /$. Os explantes foram deixados em câmara de crescimento sob uma temperatura constante de $25^{\circ} \mathrm{C} \pm 2{ }^{\circ} \mathrm{C}$ sob fotoperíodo de 16 horas. Os explantes do meio de cultura $\mathrm{MS}$ com $1.760 \mathrm{mg} / \mathrm{de} \mathrm{CaCl}_{2}$ foram os de melhor resultado, com crescimento vigoroso e presença de coloração verde intensa nas folhas. Os explantes do meio de cultura MS com $\mathbf{4 4 0} \mathrm{mg} / \mathrm{lde}$ $\mathrm{CaCl}_{2}$ não apresentaram um crescimento satisfatório, com estiolamento e coloração verde pouco intensa nas folhas; os explantes do meio de cultura $\mathrm{MS}$ com $3.520 \mathrm{mg} /$ de $\mathrm{CaCl}_{2}$, também não apresentaram um crescimento satisfatorio, pois com 10 dias de inoculaçăo já se percebia uma menor indução no crescimento, podendo tal efeito ser consequência de dois fatores: excesso de cálcio no meio de cultura ou a toxidez ocasionada pelo cloro. Descritores: Gypsophila paniculata L., micropropagação, gemas apicais, cloreto de cálcio.

\section{INFLUENCE OF CALCIUM CHLORIDE ON THE GROWTH OF Gypsophiza peniculate L. (CARYOPHYLLCEAE) EXPLANTS, CULTIVATED in vitro.}

\begin{abstract}
Shoot tips from plants still in the vegetative growth phase were used as explants. They were sterilised with tetraciclin $1 \%$ for four minutes, sodium hypochloridre (commercial sanitary water with $5 \%$ of active cloride) $20 \%(\mathrm{v} / \mathrm{v})$ for 15 minutes and alcohol $70 \mathrm{GL}$ for 2 minutes. The explants were inoculated in a growth medium MS (Murashigue \& Skoog), with different concentrations of $\mathrm{CaCl}_{2}$ : a) 440; b) 880; c) 1,760; d) 2,640 and e) 3,520 mg/. Explants were kept in a growth chamber at constant temperature $\left(25^{\circ} \mathrm{C} \pm 2{ }^{\circ} \mathrm{C}\right)$ with a photoperiod of 16 hours. The explants in the medium modified with $1,760 \mathrm{mg} /$ of $\mathrm{CaCl}_{2}$ presented the best results, with a vigorous growth and presence of intense green color on the leaves. The explants inoculated with $440 \mathrm{mg} / \mathrm{he} \mathrm{CaCl}_{2}$ did not have a satisfactory growth after 10 days of incubation, presenting estiolation and low intensity of green color in the leaves. The explants inoculated with $3,520 \mathrm{mg} / \mathrm{l}$ of $\mathrm{CaCl}_{2}$, also did not present satisfactory growth after 60 days of inoculation, probably due to an excess of calcium in the medium or chloride toxicity.

Keg Words: Gypsophila paniculata L., shoot tips, micropropagation, calcium chloride.
\end{abstract}

\section{INTRODUÇÃO}

A espécie Gypsophila paniculata L. pertence a familia Caryophyllaceae Lindl, a qual possui cerca de 80 gêneros e 2.000 espécies com ampla distribuição em todas as regiōes do globo (GEMTCHUJNICOV, 1976). Algumas espécies, são bastante conhecidas pela importância que apresentam na floricultura moderna. São exemplos, as espécies do gênero Dianthus como o Dianthus caryophyllus, que são os craveiros, especies do gênero Silene, onde são encontradas a Silene gallica que é uma planta ornamental, e principalmente as espécies do gènero Gypsophila, sendo as mais importantes a Gypsophila elegans e a Gypsophila paniculata (ANON,1978). A Gypsophila paniculata $\epsilon$ uma planta originária da Ásia Ocidental, região onde predomina o clima 
temperado. São plantas arbustivas arredondadas chegando a ter um metro de altura (BARROSO, 1978). No Brasil, são chamados comercialmente de "mosquitinho" ou ainda "branquiha". São utilizadas principalmente no arranjo de buquês florais.

Nos últimos anos, a produção de Gypsophila paniculata, tem apresentado um aumento acentuado nos principais locais de comercialização, que são o CEAGESP-SP e o leilão da HOLAMBRA, localizado em JaguariúnaSP (YANAGIZAWA,1991). A propagação desta espécie é realizada por dois métodos, através de semente e vegetativamente através da estaquia.

A propagação através da semente não é usual entre os floricultores no Brasil, pois, as sementes são todas importadas, além da dificuldade de serem encontradas no comércio. É usual no Brasil a propagação vegetativa através da estaquia. Mas esta prática apresenta várias dificuldades, pois, requer uma boa infraestrutura como casa de vegetação, assepsia no manejo do material vegetativo, entre outros cuidados.

Sabe-se que as primeiras espécies vegetais propagadas pela técnica de cultura de tecidos foram as plantas ornamentais (MOREL,1960). Este mesmo autor isolou através da cultura de meristemas, orquídeas do gênero Cymbidium, isenta de vírus patógenos a planta, propiciando grande aceitação no comércio da floricultura na época.

Dentre os poucos trabalhos publicados sobre a propagação da espécie Gypsophila paniculata L. HILL (1967) e KUSEY et al. (1980) trabalharam com a micropropagação desta espécie. HILL (1967) observou que a concentração de $0,5 \mathrm{mg} / 1$ de ácido naftaleno acético (ANA), induz rizogênese. $O$ mesmo autor, utilizando o ácido 2-4 diclorofenoxiacético, observou que a mesma dosagem usada para este regulador vegetal, resultou somente na produção de calos.

KUSEY et al. (1980) determinaram que o meio contendo sais de MS (1962) suplementado com $0,4 \mathrm{mg} / \mathrm{l}$ de tiamina $\mathrm{HCl}, 30 \mathrm{~g} / 1$ de sacarose, $100 \mathrm{mg} / 1$ de mesoinositol mais $7,0 \mathrm{~g} / 1 \mathrm{de}$ agar, com pH ajustado para 5,6 , contendo $0,05 \mathrm{mg} / \mathrm{l}$ de ácido naftaleno acético (ANA) e 1,0mg/l de 6-benzilaminopurina (6-BAP), provocou organogênese direta, a partir de explantes de gema apical.

Além da Gypsophila paniculata, existem trabalhos realizados com os cravos (Dianthus caryophyllus L.). HACKETT \& ANDERSON (1967), trabalharam com ápice caulinar e obtiveram calos, em meio WHITE
(1943) ou MS (1962) com uma concentração de $1,0 \mathrm{mg} / 1$ de ANA, houve uma ampla porcentagem de regeneração. Com a inoculação de explantes em meio basal com 5 vezes a concentração dos sais inorgânicos mais $2,0 \mathrm{mg} / 1$ de ANA, obtiveram produção de calos. Estes calos foram repicados e cultivados no mesmo tipo de meio mas com uma concentração de $5 \mathrm{mg} / \mathrm{l}$ de ANA. Observaram organogênese indireta, e com 6 a 8 semanas puderam isolar as plântulas dos calos.

\section{EARLE \& LANGHANS}

propagaram cravo em meio de cultura contendo concentrações de reguladores vegetais quase que semelhante às de KUSEY et al. (1980). Estes autores utilizaram ápices caulinares como explantes, que foram inoculados em meio sólido contendo $0,5 \mathrm{mg} / 1$ de cinetina e $0,1 \mathrm{mg} / 1$ de ANA. Após o surgimento dos primeiros perfilhos, estes foram transferidos para meio líquido com uma rotação de $1 \mathrm{rpm}$. Com este procedimento obtiveram grande quantidade de perfilhos a partir dos explantes.

Ainda com relação a propagação de cravos, ENGVILD (1972), trabalhou com a cultura de calos e suspensão de células desta mesma espécie. A cultura de calos foi mantida em meio com a metade dos sais de MS (1962), 3\% de sacarose, $100 \mathrm{mg} / 1$ de mesoinositol, $0,5 \mathrm{mg} / 1$ de tiamina $\mathrm{HCl}$, piridoxina $\mathrm{HCl}$ e ácido nicotínico com $10,0 \mathrm{~g} / \mathrm{lk}$ de agar. Utilizando este meio de cultura com $3 \times 10^{-6} \mathrm{M}$ de ácido indol-acético (IAA), combimado com $3 \times 10^{-6} \mathrm{M}$ de benzilaminopurina (BAP), conseguiu-se um crescimento ótimo dos calos. Diversas tentativas para a indução da organogênese em calos foram realizadas, mas nenhuma apresentou sucesso.

A palavra Gypsophila vem da união de duas palavras gregas que são: Gypso, que significa gesso e phyllum, que exprime afinidade. $O$ gesso é utilizado na agricultura como fornecedor, principalmente de Cálcio, entre outros nutrientes. Intuitivamente os floricultores da região de AtibaiaSP, a $60 \mathrm{~km}$ de São Paulo, utilizam doses elevadas de calcário e gesso na produção desta espécie vegetal.

O Cálcio possui funções conhecidas como o de função estrutural, absorção iônica, particularmente na correção do efeito desfavorável da concentração hidrogeniônica excessiva, ativador de enzimas entre outras (MALAVOLTA,1980).

Com o presente trabalho, procurou verificar a influência do Cloreto de Cálcio $\left(\mathrm{CaCl}_{2}\right)$, no crescimento in vitro de Gypsophila paniculata 
L, bem como fornecer subsídios para a micropropagação desta espécie.

\section{MATERIAL E MÉTODOS}

O presente trabalho foi conduzido no Laboratório de Cultura de Tecidos Vegetais do Departamento de Botânica da Escola Superior de Agricultura "Luiz de Queiroz" - Universidade de São Paulo.

Foram utilizados como explantes gemas apicais com tamanho padronizado de $2,5 \mathrm{~cm}$. Todas as gemas foram coletadas de plantas de Gypsophila paniculata L. em fase de crescimento vegetativo.

Os explantes foram esterilizados inicialmente em água corrente com detergente comercial por 15 minutos e lavados com água destilada. Após, o explante foi mergulhado em solução de tetraciclina a $1 \%$ por 4 minutos, no interior da câmara de fluxo contínuo, em seguida mergulhado em solução de hipoclorito de sódio (água sanitária comercial, contendo $5,0 \%$ de cloro ativo) $20 \%(\mathrm{v} / \mathrm{v})$ durante 20 minutos, e finalmente em álcool $70^{\circ} \mathrm{GL}$ por 2 minutos. Após lavadas em água destilada e autoclavada, os explantes foram colocadas em placas de Petri.

Os explantes esterilizados foram inoculados em meio de cultura contendo sais de MURASHIGUE \& SKOOG (1962), com modificações na concentração de $\mathrm{CaCl}_{2}$ :

a) Sais de MURASHIGUE \& SKOOG (1962) com a concentração original de $440 \mathrm{mg} / \mathrm{l}$ de $\mathrm{CaCl}_{2}$ (T1); b) Sais MS com a concentração de $880 \mathrm{mg} / 1$ de $\mathrm{CaCl}_{2}$ (T2);

c) Sais de MS com a concentração de $1760 \mathrm{mg} / 1$ de $\mathrm{CaCl}_{2}$ (T3);

d) Sais de MS com a concentração de $2640 \mathrm{mg} / \mathrm{l}$ de $\mathrm{CaCl}_{2}$ (T4);

e) Sais de MS com a concentração de $3520 \mathrm{mg} / 1$ de $\mathrm{CaCl}_{2}$ (T5).

Todos os meios de cultura foram acrescidos com $30 \mathrm{~g} / 1$ de sacarose, $0,4 \mathrm{mg} / 1$ de tiamina, 100mg/l de mesoinositol, 7,0g/l de agar e $\mathrm{pH}$ ajustado para 5,8. Utilizaram-se neste trabalho, tubos de ensaio $(15 \times 2,5 \mathrm{~cm})$, com $10 \mathrm{ml}$ de meio de cultura em cada tubo e fechados com tampas de aço inox. Os meios foram autoclavados sob uma pressão de $137 \mathrm{~kg} / \mathrm{cm}^{2}$, à temperatura de $121^{\circ} \mathrm{C}$ por 15 minutos.
Após a inoculação dos explantes, estes foram acondicionados em câmara de crescimento sob uma temperatura constante de $25^{\circ} \mathrm{C} \pm 2^{\circ} \mathrm{C}$, sob uma iluminação de $75 \mu \mathrm{mol} \mathrm{s}^{-1} \mathrm{~m}^{2}$ de intensidade luminosa (lâmpadas fluorescentes luz do dia) por um fotoperíodo de 16 horas.

\section{RESULTADOS E DISCUSSÃO}

A TABELA 1 apresenta os dados de crescimento em altura dos explantes, aos 25 dias de cultura in vitro. A análise de variância mostrou diferenças significativas entre os tratamentos. No teste de comparação de médias a $1 \%$, verifica-se superioridade do tratamento $\mathrm{T} 3$ sobre os demais, sendo que $\mathrm{T} 1, \mathrm{~T} 2$ e $\mathrm{T} 4$ situaram na faixa intermediária, e o tratamento T5 o de menor resultado.

A TABELA 2 contém os dados médios do peso da matéria seca dos explantes, após 25 dias de cultura in vitro. O teste de comparação de médias (teste de Tukey) mostrou em nível de $1 \%$ a superioridade do tratamento T3 sobre os demais, comprovando os resultados do teste observado na TABELA 1. Passados exatamente 10 dias após a inoculação dos explantes, observou-se visíveis diferenças no crescimento dos explantes, nos vários meios de cultura (Figura 1). Os explantes que mais se destacaram, foram os do meio de MS (1962), contendo $1760 \mathrm{mg} / \mathrm{l} \mathrm{de} \mathrm{CaCl}_{2}$, além do maior crescimento, os explantes apresentavam-se com pouco ou nenhum estiolamento, apresentando vigor e coloração verde intensa nas folhas.

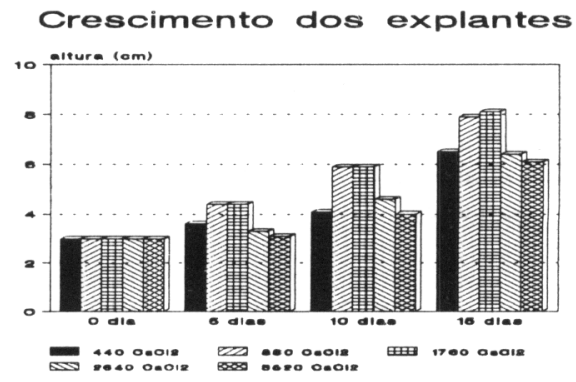

Figura 1 - Crescimento dos explantes de $G$. paniculata nas diferentes concentrações de $\mathrm{CaCl}_{2}$ : T1 (meio MS com $440 \mathrm{mg} / \mathrm{l}$ de $\mathrm{CaCl}_{2}$; $\mathrm{T} 2$ (meio MS com $880 \mathrm{mg} / \mathrm{l}$ de $\mathrm{CaCl}_{2}$ ); T3 (meio MS com 1.760 $\mathrm{mg} / 1$ de $\mathrm{CaCl}_{2}$ ); T4 (meio MS com $2.640 \mathrm{mg} / \mathrm{l} \mathrm{de} \mathrm{CaCl}_{2}$ ); T3 (meio MS com $3.520 \mathrm{mg} / \mathrm{l} \mathrm{de} \mathrm{CaCl}_{2}$ ). 
TABELA 1 - Efeito da concentração do $\mathrm{CaCl}_{2}$ no crescimento em altura dos explantes de G.paniculata $\mathrm{L}$., 25 dias após a inoculação nos meios de cultura MS modificado.

\begin{tabular}{lc}
\hline \multicolumn{1}{c}{ Tratamentos } & Altura dos Explantes (cm) \\
\hline $\mathrm{T} 1$ - $440 \mathrm{mg} \mathrm{CaCl}_{2} / 1$ & $7,180 \mathrm{AB}$ \\
$\mathrm{T} 2-880 \mathrm{mg} \mathrm{CaCl} / 1$ & $6,704 \mathrm{~B}$ \\
$\mathrm{~T} 3-1.760 \mathrm{mg} \mathrm{CaCl} / 1$ & $8,326 \mathrm{~A}$ \\
$\mathrm{~T} 4-2.640 \mathrm{mg} \mathrm{CaCl}_{2} / 1$ & $4,364 \mathrm{BC}$ \\
$\mathrm{T} 5-3.520 \mathrm{mg} \mathrm{CaCl}_{2} / 1$ & $6,990 \mathrm{C}$ \\
\hline $\mathrm{F}$ (trat.) & $16,912 * *$ \\
$\mathrm{CV}(\%)$ & 9,846 \\
\hline \hline
\end{tabular}

** Significativo ao nivel de $1 \%$ de probabilidade

OBS: Letras diferentes, numa mesma coluna, indicam diferenças significativas entre as médias, pelo teste de Tukey.

TABELA 2 - Efeito da concentração do $\mathrm{CaCl}_{2}$ na produção de matéria seca (mg) dos explantes de G.paniculata L., 25 dias após a inoculação nos meios de cultura MS modificado.

\begin{tabular}{|c|c|}
\hline Tratamentos & Altura dos Explantes $(\mathrm{cm})$ \\
\hline $\mathrm{T} 1-440 \mathrm{mg} \mathrm{CaCl} / 1$ & 35,32 B \\
\hline $\mathrm{T} 2-880 \mathrm{mg} \mathrm{CaCl} / 1$ & $40,32 \mathrm{AB}$ \\
\hline $\mathrm{T} 3-1.760 \mathrm{mg} \mathrm{CaCl} \mathrm{l}_{2} / 1$ & $55,74 \mathrm{~A}$ \\
\hline $\mathrm{T} 4-2.640 \mathrm{mg} \mathrm{CaCl} / 1$ & $39,26 \mathrm{AB}$ \\
\hline $\mathrm{T} 5-3.520 \mathrm{mg} \mathrm{CaCl} / \mathrm{l}$ & $33,24 \quad \mathrm{~B}$ \\
\hline F (trat.) & $6,848 * *$ \\
\hline CV (\%) & 18,536 \\
\hline
\end{tabular}

** Significativo ao nível de $1 \%$ de probabilidade

OBS: Letras diferentes, numa mesma coluna, indicam diferenças significativas entre as médias, pelo teste de Tukey.

O estiolamento foi freqüente nos explantes inoculados no meio de cultura com sais de MS com a concentração original do sal $\mathrm{CaCl}_{2}$, e para explantes deste meio de cultura diferentemente do anterior, as folhas não apresentavam-se com a coloração verde intensa. (1) explantes do meio de cultura MS com $2.640 \mathrm{mg} / 1$ e $3.520 \mathrm{mg} / 1 \mathrm{de} \mathrm{CaCl}_{2}$, apresentaram crescimento reduzido. No meio de cultura MS com $3.520 \mathrm{mg} / 1$ de $\mathrm{CaCl}_{2}$, após o $10^{\circ}$ dia de inoculação, observouse um crescimento muito lento, prejudicado, com a provável consequiência do excesso de $\mathrm{Ca}$ ou pela toxidez do Cloro no meio de cultura. Analisando-se os pesos das matérias secas, após 20 dias de meio de cultura, notou-se superioridade dos explantes do meio MS, contendo $1760 \mathrm{mg} / 1$ de $\mathrm{CaCl}_{2}$ sobre os demais, alcançando em algumas repetições, $o$ dobro do peso sobre os menores.

$E$ interessante assinalar que, diferente das maiorias das culturas, a porcentagem de enraizamento é muito pequena (4\%). Esta baixa taxa de enraizamento pode ser prejudicial na etapa da aclimatação desta cultura. KUSEY \& HAMMER (1980) conseguiram o enraizamento, somente após 
- tratamento dos explantes com ácido naftaleno acético (ANA) ou ácido indolbutírico (IBA). Ainda em relação a rizogênese, HILL (1967) obteve o enraizamento a partir de calos em meio de cultura com $0,5 \mathrm{mg} / \mathrm{l}$ de ÁNA, com baixa dosagem de $2-4$ diclorofenoxiacético (2-4D).

\section{CONCLUSÕES}

1 - O meio de cultura que mostra uma melhor resposta para o crescimento de explantes da espécie Gypsophilla paniculata L., é o meio de cultura com sais de MURASHIGE \& SKOOG (1962), com a concentração de $1.760 \mathrm{mg} / \mathrm{l}$ de $\mathrm{CaCl}_{2}$ (T3).

2 - O meio de cultura com sais de MS com $\mathbf{4 4 0}$ $\mathrm{mg} / \mathrm{l}$ de $\mathrm{CaCl}_{2}$ não se mostrou satisfatório, devido ao alto índice de estiolamento ocorrido nos explantes (T1).

3 - Não houve efeito positivo dos meios de cultura estudados na rizogênese dos explantes.

\section{REFERÊNCIAS BIBLIOGRÁFICAS}

ANON. Gypsophilla clean-up. Grower, London, v.90, n.18, p.869, 1978.

BARROSO, G.M. Familia Caryophyllaceae Lindl. In: .Sistematica das angiospermas do Brasil. São Paulo: EDUSP, v.1, p.103-108, 1978.

EARLE, E.D.; LANGHANS, R.W. Canations propagation from shoot tips cultured in liquid medium. HortScience, Saint Paul, v.10, n.6, p.608-610, 1975.

ENGVILD, K.C. Callus and cells suspension cultures of carnation. Physiologia Plantarum, Lancaster, v.26, p.62-66, 1972.
GEMTCHUJNICOV, I.D. Familia Cariophilaceae Lindl. In: GEMTCHUJNICOV, I.D. Manual da taxonomia vegetal, São Paulo: Ceres, v.1, p.228$230,1976$.

HACKETT, W.P.; ANDERSON, J.M. Asept multiplication and maintenance of differentiated carnation shoot tissue derived from shoot apices. American Society for Horticultural Science Journal, Alexandria, v.90, p.365-369, 1967.

HILL, G.P. Root formation in callus culture of Gypsophila paniculata L. Naturwissenschaften, Berlin, v.54, p.522, 1967.

KUSEY, W.E. Jr.; HAMMER, P.A.; WEILER, T.C. In vitro propagation of Gypsophila paniculata L. Bristol Fairy. HortScience, Saint Paul, v.15, p.600-601, 1980.

MALAVOLTA, E. Macroelemento catiônico: cálcio. In: - Elementos de nutriçáo mineral de plantas. São Paulo, Ed. Agronômica Ceres, 1980. v.1, p.163-166.

MOREL, G.M. Producing virus free Cymbidiuns. American Orchid Society Bulletin, Palm Beach, v.29, p.495-497, 1960.

MURASHIGUE, T. \& SKOOG, F. A revised medium for rapid growth and biossays with tobacco tissue cultures. Physiologia Plantarum, Kobenhawn, v.15, p.473-497, 1962.

WHITE, P.R. A handbook of plant tissue culture. Lancaster: Jacques Cattel, 1943. 277p.

YANAGIZAWA, S.S. Uma cultura que rende dinheiro. Informe GEP/DESR, Piracicaba, v.4, n.7, p.15, 1991.

Enviado para publicação em 05.10 .92

Aceito para publicação em 08.08 .93 